\title{
Niclas Schaper*
}

\section{Theoretical Substantiation of Human Resource Management from the Perspective of Work and Organisational Psychology ${ }^{* *}$}

In the article it is tried to substantiate further developments in human resource management with reference to the competency approach in work and organisational psychology. First the objectives of scientific and applied research in work and organisational psychology are lined out. Then the competency approach is discussed as a helpful concept to different challenges of human resource management. With reference to this assumption three different theoretical and methodological perspectives are introduced which focus on different aspects of understanding, analysing, diagnosing and developing competencies. These include the action and self-organisation theory perspectives of competencies and the competency modelling perspective.

Key words: Work and Organisational Psychology, Action Theory, Self-organisation Theory, Competency Modelling Approach, Competency Based Human Resource Management

Prof. Dr. Niclas Schaper, University of Paderborn, Chair of Work and Organisational Psychology (H 4.132), Warburger Straße 100, D - 33098 Paderborn, Germany, Phone: ++49 5251 602901, Fax: ++49 5251 603528. E-Mail: schaper@hrz.upb.de.

** Article received: February 26, 2004

Revised version accepted after double blind review: April 24, 2004. 


\section{Introduction}

The understanding and effective management of people in organisations is the core issue of human resource management. As a scientifically substantiated discipline of business management and administrative science it is based on theoretical models and empirically proven concepts and methods. The theories, concepts and methods are derived from a diversity of other disciplines and fields of scientific research. Thus, the theoretical and methodological approach to HRM issues is in most cases eclectic because of their complex and not well defined characteristics. One of these disciplines in which HRM is rooted is psychology - especially work and organisational (w/o)psychology.

W/o-psychology is the science of behaviour and other human variables at work and in organisations. It is an applied science which draws from a broad and diverse theoretical basis (Frieling/Sonntag 2000). This specifically includes psychological theories of cognition, motivation, learning and social behaviour which are used to describe, explain, predict, and control human behaviour at work or in organisational settings. These theoretical concepts are not only helpful to guide psychological research in workplaces and organisations, they are also used to solve practical problems especially in the field of human resource management. Psychological theories of work motivation, e.g., have been used to develop job analysis techniques to diagnose motivational dimensions of work. Based on these theories, interventional concepts to (re)design jobs for the enhancement of work motivation have also been created and positively evaluated. In accordance with Lewin's (1936) sentence "Nothing is as practical as a good theory" one of the central goals of applied research in w/o-psychology is that the development of diagnostic and interventional concepts or tools should be theoretically substantiated and reflect sound psychological models. Based on this philosophy researchers in w/o-psychology have developed a wide spectrum of theoretically substantiated diagnostic and interventional approaches and methods. These concepts are in fact related to many of the core areas of human resource management like needs or requirements analyses, personnel recruitment and selection, personnel development und health prevention, enhancement of work motivation and performance improvement or the support of adequate leadership behaviour.

Concerning the question of how theoretical developments in the field of w/opsychological could substantiate approaches in human resource management the author is somehow in a dilemma. An adequate answer would result in an endless enumeration of psychological concepts which have proven to be useful in applied organisational contexts or to support human resource management issues. Alternatively, one could select promising theoretical models or approaches of w/o-psychology which are justified under a certain perspective or dependant on defined criteria. Following the alternative proposal I chose to focus on competency-oriented psychological models which in my opinion seem promising concepts for the theoretical and methodological substantiation of human resource management. This selection is justified with reference to challenges human resource management is facing in today's organisational environments. The reader, though, has to keep in mind that this choice is somehow arbitrary or subjective. 


\section{Challenges of human resource management}

Human resource management is operating in dynamic organisational environments. The forces which influence especially the management of personnel issues are characterised by Scholz (2000) as technological dynamics, market dynamics, organisational dynamics, value dynamics and globalisation. Concerning technology, companies and their employees are faced with increasingly shorter product cycles and half-life periods of technological knowledge. This leads to continuous changes of job requirements. Additionally, the implementation of computer and internet technology, which led to fundamental changes of work processes and organisational structures, imposes continuous developmental demands on employees. Market dynamics are characterised by a shift from making products to providing services. This requires advanced social competencies of the employees to additionally satisfy customer needs. The market has also become much more aggressive and turbulent, putting companies under enormous economic pressures and adaptation needs concerning the quantity and quality of their personnel. Continuous organisational changes become the normal state of affairs in firms. These changes include business reengineering, downsizing, merging, decentralising, and the loosening of organisational boundaries. On the individual level, they lead to faster changes in employees' roles as well as increased responsibilities and tasks on the job. Also, power or information hierarchies change in favour of the growing relevance of networks. On the societal level, there are also changes concerning the importance of certain values that influence human resource management. Different studies (e.g. von Rosenstiel 1987) show that traditional values like obedience, discipline, or self-control etc. are becoming less important in comparison to values like self-realisation, freedom, and independence. Because work motivation and organisational commitment are dependent on the correspondence of the individual's values and the company's culture, it is important to select employees who fit to the culture and/or to change the company's culture in accordance to new values. Globalisation also imposes new demands on human resource management which are characterised by managing a larger spectrum of cultural diversity, managing and supporting personnel work at locations in other countries, and preparing and supporting expatriates and their families before, while, and after they are abroad.

- Luthans (1995, p. 4) describes similar challenges as trends that will reshape the workplace including the following:

- "The traditional hierarchical organisation will give way to a variety of organisational forms, the network of specialists foremost among these.

- Technicians, or knowledge workers will replace manufacturing operatives as the worker elite.

- The vertical division of labour will be replaced by a horizontal division.

- Work itself will be redefined: constant learning, more high-order thinking, less of routine tasks."

The described trends imply consequences for almost all functions of human resource management but especially for the recruitment and development of human resources, and the performance management function. In accordance with the perspective of personnel as a company's strategic resource recruiting and developing human re- 
sources and their competencies becomes one of the central tasks (Sonntag/Schaper 1999).

Baethge and Schiersmann (2000) describe how personnel development functions have changed due to the mentioned organisational dynamics. They characterise the changes generally as a development from vocation- and function-oriented to processoriented personnel development. This implies that besides teaching job-specific qualifications the development of social and self-management competencies becomes increasingly important. Thus, people have to be enabled to become more self-reliant in managing their learning demands on the job. In accordance with the content shift, learning takes place not only in courses, but increasingly in job-integrated learning arrangements, which rely on self-organised cooperative learning, and the use of elearning components. Also, learning needs are defined with reference to process requirements and organisational changes and far less with reference to vocational demands. Concerning the roles of personnel developers it has to be noted that a change from teaching to counselling and supporting functions of learning and development processes occurs. Furthermore, certifying informal learning processes and managing the quality of personnel development functions becomes important. The next sections show that a competency based perspective of human resource management can substantially contribute to managing these challenges.

\section{Competency approaches in w/o-psychology}

Competencies are defined from three different perspectives in w/o-psychology: The perspective of action theory, self-organisation theory and the competency modelling approach. The three perspectives are introduced with reference to their definition of competencies, the basic theoretical assumptions, and their diagnostic and developmental implications for human resource management.

\section{The action theory perspective}

One important psychological theory in which the concept of competence plays an important role is "action theory" (Frese/Zapf 1994; Hacker 1998). Action theory is a general theory of work behaviour which defines competence as the ability to act selfresponsibly in complex situations on the job. In order to act competently, an individual hast to develop goal-oriented behaviour. This means that learners have to develop behavioural abilities, which are regulated by action goals, well organised plans of actions, and feedback processes to monitor and determine if goals have been reached. Action theory is mainly cognitively oriented. It thus focuses on the role of work tasks and their redefinition as goals, the hierarchical structure of action organisation and its implications for action planning and levels of regulation (sensori-motor level, level of flexible action patterns, intellectual level), and its role concerning monitoring and feedback processes while executing actions. In supplemental approaches, the motivational and social aspects of goal-oriented behaviour have also been theoretically modelled (Hacker 1998; Bergmann/Richter 1998).

Concerning the management of human resources, action theory and it's concept of competence can help to understand which internal resources are needed to regulate work activities effectively and how to identify these resources. This refers to action- 
oriented knowledge structures (operative image systems), routine actions, cognitive strategies, and heuristics, different action regulation levels, as well as action related communication, cooperation and meta-cognition aspects. Action theory-oriented task and job analysis techniques provide tools to identify competency demands of this kind.

These competency analyses have implications for task and work design. Especially the principles of "complete actions" (possibilities to plan and control and not just execute actions) and "provision of feedback" (through the action itself or its results) have to be considered when designing tasks or jobs that enhance competency development.

Furthermore, action theory offers well-proven pedagogical concepts of how to acquire such competencies (Bergmann 1999). The principles to teach and coach competence development under this perspective stress especially work- and transferoriented learning. Therefore the learner is involved in active and real-life task oriented learning experiences, and he is coached to systematically reflect and evaluate his learning actions in comparison with effective strategies of action regulation.

Taken together, the competence concept of action theory has important implications for the understanding and support of personnel development, requirements analysis and work design issues. Thus, action theory and its competency concept enriche the theoretical substantiation of human resources management from a task- and worker-oriented perspective.

\section{The self organization theory perspective}

The self-organisation theory perspective focuses on demands concerning working and learning in modern organisational structures. These demands or work situations are characterised as highly complex and uncertain. Goals that have to be accomplished and/or starting situations and framework conditions are ill-defined in those work contexts. Self-organisation theorists claim that another type of competencies is necessary to manage such situations as discussed in the first theoretical perspective (Erpenbeck/v. Rosenstiel 2003). In addition to abilities of action-regulation, competencies are required to think and behave in a self-organised way in new, uncertain situations and to solve relevant problems creatively.

Concepts of self-organisation theory also describe which strategies are required to manage such complex situations and which factors influence the development of selforganisation competencies. The strategies are characterised as "evolutionary" (Erpenbeck/von Rosenstiel 2003). They include e.g. identifying cooperatively which results and criteria are adequate to meet the goals, searching and trying out different solutions, optimising solution procedures stepwise, iteratively adapting evaluation criteria etc. As influence factors for competence development are discussed: a climate of openness and error tolerance, sufficient communication and cooperation possibilities, development-oriented values, etc. These aspects can altogether be summarised as characteristics of a supportive learning culture (Schaper/Friebe/Sonntag 2003).

Under this theoretical perspective competencies are defined as dispositions to act in self-organised ways in complex ill-defined situations. This includes all personal requirements that are needed in those contexts. The spectrum reaches from job-specific 
skills and knowledge to job-unspecific cognitive abilities, social skills, motivational and volitional skills, and personality aspects.

Implications of the self-organisation theory perspective for human resource management are two-fold. First, they are concerned with the question of how to diagnose competencies or dispositions of self-organised actions. The proponents of the theory plead for a pluralism of methodological approaches. This means especially that besides objective tests of competence also ideographic methods should be used. Objective diagnostic instruments like performance tests, observational systems or questionnaires focus on the precise measurement and evaluative comparison of the status of individual competencies. Subjective diagnostic methods like interviews, self-evaluations, ethnographic or biographical methods are more oriented towards understanding processes of competence development, the conditions and contexts of competence usage, and correlations between competency profiles and work effects or results. Thus, there is not one and only preferred diagnostic method to measure competencies under this perspective. It is rather suggested that depending on the specific diagnostic question an adequate method or combination of methods ought to be selected.

Secondly, the implications refer to recommendations how to develop competencies. To develop competencies for self-organised acting traditional instructional methods are not adequate, because those competencies can't be taught in lectures or in exercises. It is instead important to arrange learning environments that support active and problem-oriented learning where learners are confronted with authentic, challenging tasks. Furthermore, learning of self-organisation competencies should take place in the context of use. So, learning on the job is in most cases recommended. This, however, does not mean that instructional support is not necessary. In the contrary, a supportive learning infrastructure, which includes e.g. adequate learning media, tutoring or mentoring offers, evaluation elements etc., must carefully be designed and implemented. The competency development should also be embedded in adequate social learning contexts because communication and cooperation demands enhance development processes and/or represent important learning requirements. This provides at least opportunities for the exchange of learning experiences with other learners and in its maximal realisation a participation in a community of practice.

In summary, the self-organisation theory perspective offers also interesting concepts for requirements analysis, diagnostic issues and developmental questions. This approach is especially focused on performance potentials and self-concept oriented variables. Its contributions to substantiate human resource management are basically developed from a culture- and worker-oriented perspective.

\section{The competency modelling approach perspective}

In contrast to the first two approaches, competency modelling focuses on analytical and diagnostic issues of human resource management. Its primary goal is to identify the essential skills, knowledge, and personal characteristics needed for successful performance in a job and to ensure that human resource management focuses on developing these. Under this perspective a competence is defined as "an underlying characteristic of a person which results in effective and/or superior performance on the job" (Klemp 1980, p. 21). More precisely, Spencer and Spencer (1983) characterise that the 
underlying personal characteristics consist of specific configurations of motives, traits, self-concept variables (a person's attitudes, values, or self images e.g. self-confidence), knowledge, and skills which indicate ways of behaving or thinking in a job - generalized across situations. This approach is rooted in the work of McClelland (1973) who developed a certain method (behavioural event interview) to identify performance relevant job requirements which he called competencies. The approach is based on the criticism that common ability tests based on general psychological constructs (e.g. intelligence or achievement motivation) do not sufficiently focus on job relevant personnel characteristics.

To describe job relevant personnel characteristics competency models are developed. These models are derived from two different analytical approaches: an empirically oriented bottom-up approach and a strategically oriented top-down approach. The bottom-up approach focuses on the empirical analysis of effective and superior job performance by interviewing job incumbents. In so called "behavioural event interviews" (Spencer/Spencer 1983) they are asked how they managed typical and difficult situations on the job. Top- and low-performers are then compared to identify the differences between effective and non-effective behavioural indicators of job competencies. This approach focuses on the actual state of relevant job competencies. In the top-down or strategy-oriented approach the focus is on job competencies which will become relevant in the future and are needed to fulfil strategic goals of the company. Here, the competencies are generated in strategic workshops with members of the top and upper management. The intention of this method is to align the competency model with the company's core competencies and its future business goals. Both approaches can be combined to get empirically validated and strategy-oriented models for a competency-based human resource management.

Competency models are not only used for selection purposes. They rather serve as a general framework for human resource management. Consequently, a variety of human resource management instruments and activities can be derived from competency models. Spencer and Spencer (1983) describe competency based selection instruments (e.g. competency based interviewing), performance management, training activities, succession planning, career pathing, and payment. With this approach it is also possible to match and coordinate activities like recruiting, placement, retention, and promotion by using a uniform conceptual basis. Furthermore, competency modelling supports the alignment of human resource management activities to the business strategy. Also, organisational change processes or the implementation of a supportive learning and performance culture can be enhanced by this approach (Lucia/Lepsinger 1999).

Taken together, the competency modelling approach supports the integration of different human resource management activities like e.g. selection, training, performance management and career development because all refer to the competency model. The model enables a consequent treatment of a uniform design of human resource management activities. In addition, this approach serves two complementary goals of human resource management:, it is directed to the individual's development and also to the accomplishment of business goals. 


\section{Conclusions}

The intention of this article was to show that the competency approach in w/opsychology offers some promising theoretical and methodological concepts to substantiate further developments in human resource management. The competence concept was discussed as a helpful concept for different challenges faced by human resource management in many companies. Therefore three different theoretical and methodological perspectives of this approach were introduced which focus on different aspects of understanding, analysing, diagnosing and developing competencies.

The action and self-organising theory perspectives specifically offer theoretical concepts to understand and explain what competencies are, how they influence work and organisational behaviour and how they can be developed. Implications for human resource management activities are partly well developed, but they also leave a lot of questions unanswered (e.g. through which methods action regulation abilities can be diagnosed). The competency modelling approach, in contrast, supports a much more systematic design and also the consideration of strategic aspects of human resource management activities. A shortcoming of this approach, however, is its focus on methodological questions of analysing, diagnosing and enhancing performance relevant competencies. The theoretical concepts of this approach need further development.

A promising perspective of the competency approach could be developed by integrating the three perspectives. An integrative approach could for instance contribute to more deductive and better substantiated procedures for the definition and classification of competencies. Also, the mono-methodological approach of the competency modelling concept could be enlarged by considering the analytical and diagnostic concepts of the other two approaches. First thoughts in this direction are developed in the handbook of Erpenbeck and von Rosenstiel (2003).

\section{References}

Baethge, M./Schiersmann, Ch. (2000): Prozessorientierte Arbeits- und Betriebsorganisation - Konsequenzen für die Anforderungen an „Lebensbegleitendes Lernen“. In: F. Achtenhagen/W. Lempert (Hrsg.): Lebenslanges Lernen im Beruf. Seine Grundlegung im Kindes- und Jugendalter (II). Opladen: Leske + Budrich.

Bergmann, B. (1999): Training für den Arbeitsprozess. Entwicklung und Evaluation aufgaben- und zielgruppenspezifischer Trainingsprogramme. Zürich: vdf Hochschulverlag AG an der ETH Zürich.

Bergmann, B./Richter, P. (1994): Die Handlungsregulationstheorie. Göttingen: Hogrefe.

Erpenbeck, J./Rosenstiel, L. v. (2003): Einführung. In: J. Erpenbeck/L. v. Rosenstiel (Hg.): Handbuch Kompentenzmessung. Erkennen, verstehen und bewerten von Kompetenzen in der betrieblichen, pädagogischen und psychologischen Praxis (S. IX-XL). Stuttgart: Schäffer-Poeschel.

Frese, M./Zapf, D. (1994): Action as the Core of Work Psychology: A German Approach. In: H. C. Triandis/M. D. Dunnette/L. M. Hough (eds.): Handbook of industrial and organizational psychology (pp. 271-340): Palo Alto: Consulting Psychologists Press.

Frieling, E./Sonntag, Kh. (1999): Lehrbuch Arbeitspsychologie (2. überarb. Auflage). Bern: Hans Huber.

Hacker, W. (1998): Allgemeine Arbeitspsychologie. Psychische Regulation von Arbeitstätigkeiten. Bern: Hans Huber.

Klemp, G. O. (1980): The Assessment of Occupational Competence. Washington, D. C.: Report of National Institute of Education.

Lewin, K. (1936): Principles of topological psychology. New York: Johnson. 
Lucia, A. D./Lepsinger, R. (1999): The Art and Science of Competency Models. Pinpointing Critical Sucess Factors in Organizations. San Francisco: Jossey-Bass Pfeiffer.

Luthans, F. (1995): Organizational Behavior (7. Auflage). New York: McGraw-Hill.

McClelland, D. C. (1973): Testing for competence rather than for intelligence. In: American Psychologist, $28,1-14$.

Rosenstiel, L. v. (1987): Wandel in der Karrieremotivation. Verfall oder Neuorientierung? In: L. v. Rosenstiel/H. E. Einsiedler/R. K. Streich (Hg.): Wertewandel als Herausforderung für die Unternehmenspolitik (S. 35-52): Stuttgart: Schäffer-Poeschel.

Schaper, N./Friebe, J./Sonntag, Kh. (2003): Lernkulturen - eine explorative Studie mit Experten aus der Unternehmenspraxis und der angewandten Forschung. In: Wirtschaftspsychologie, 3, 80-82.

Scholz, Ch. (2000): Personalmanagement. München: Vahlen.

Sonntag, Kh./Schaper, N. (1999): Förderung beruflicher Handlungskompetenz. In: Kh. Sonntag (Hg.): Personalentwicklung in Organisationen, 2. erweit. \& überarb. Auflage (S. 211-244). Göttingen: Hogrefe.

Spencer, L. M./Spencer, S. M. (1993): Competence at work. Models for Superior Performance. New York: John Wiley \& Sons. 